\title{
GAMIFICAÇÃO: MODELAGEM DE CONTEÚDOS PARA PROGRAMAS E APLICATIVOS EDUCATIVOS NO AMBIENTE DA TV DIGITAL INTERATIVA
}

\author{
Marcos AMÉRICO ${ }^{1}$ \\ Shelley Costa NAVARI ${ }^{2}$ \\ Francisco Rolfsen BELDA ${ }^{3}$
}

RESUMO: Com a implantação da TV Digital no Brasil, surge a necessidade de se fomentar a concepção e produção de conteúdos audiovisuais interativos de qualidade que apresentem mensagens educativas a partir do Edutretenimento. Este estudo propõe a aplicação da gamificação como elo comunicacional para incentivar e modificar o comportamento dos usuários, através de uma narrativa que incentive a motivação intrínseca para o entretenimento e o aprendizado nesses meios. Existem poucos modelos de roteiros para a produção de aplicativos, sobretudo educacionais, com aplicações interativas simultâneas para o fluxo televisivo ou para o conteúdo complementar da programação ofertada. Por essa razão, é atribuída uma atenção especial ao roteiro, em virtude de se inserir, em sua construção, os elementos que compõem a mecânica e a dinâmica dos jogos. Como resultado, é apresentado o verbete "Gamificação-TVDI", bem como o desenvolvimento de uma metodologia de modelagem de conteúdo e de processo, apoiada em mapas conceituais, wireframes e roadmaps, fundamentando a concepção e a elaboração de um protótipo de roteiro com elementos de gamificação para programas educativos e seus aplicativos de interação.

PALAVRAS-CHAVE: Gamificação. TV digital interativa. Roteirização. Aplicativo educativo. Modelagem de conteúdo e processo.

\section{Introdução}

Este trabalho apresenta uma metodologia para o desenvolvimento de sistemas de gamificação em aplicativos educativos para o ecossistema da televisão digital interativa, com o escopo de nortear pesquisas que tenham por objetivo incentivar e modificar o comportamento dos usuários no processo de ensino/aprendizagem em contextos

\footnotetext{
${ }^{1}$ Doutor em Educação para a Ciência . UNESP - Universidade Estadual Paulista. Pós-Doutor. UNLaM Universidad Nacional de La Matanza. Docente Programa de Pós-Graduação em Televisão Digital: Informação e Conhecimento. UNESP - Universidade Estadual Paulista. Faculdade de Arquitetura Artes e Comunicação. Bauru - SP - Brasil. 17033-360 - tuca@ faac.unesp.br.

${ }^{2}$ Mestranda do Programa de Pós-Graduação em Televisão Digital: Informação e Conhecimento. UNESP - Universidade Estadual Paulista. Faculdade de Arquitetura Artes e Comunicação. Bauru - SP - Brasil. 17033-360 - scostanavari@yahoo.com.br.

${ }^{3}$ Doutor em Engenharia de Produção. USP - Universidade de São Paulo. Docente Programa de PósGraduação em Televisão Digital: Informação e Conhecimento. UNESP - Universidade Estadual Paulista. Faculdade de Arquitetura Artes e Comunicação. Bauru - SP - Brasil. 17033-360 - belda@ faac.unesp.br.
} 
formais, informais e não formais voltados para o ambiente proporcionado pela implantação do SBTVD-t - Sistema Brasileiro de TV Digital Terrestre.

A partir da construção de um modelo de conteúdo e processo, o presente trabalho procura fornecer subsídios para a construção de projetos de aplicativos educativos, cujo ponto de partida inicia-se com o desenvolvimento de roteiros interativos específicos para este objetivo. Em virtude de a produção interativa de conteúdo para a televisão digital seguir métodos diferenciados da produção convencional, a pesquisa propõe uma modelagem para o desenvolvimento do roteiro, voltado para as novas mídias, principalmente utilizando a linguagem dos jogos digitais, a fim de favorecer a comunicação bidirecional, em que o usuário tenha a possibilidade de intervir na lógica dos conteúdos recebendo o feedback esperado. Para tanto busca responder algumas questões, como: (1) Até que ponto a construção de significados e o encadeamento de ações e elementos visuais e interativos no roteiro, em uma relação de causa e efeito, pode contribuir para o engajamento do usuário frente à oferta de conteúdos interativos? (2) Quais os limites e as possibilidades ao se trabalhar os elementos dos jogos no desenvolvimento do roteiro audiovisual? (3) De que forma as notações textuais e gráficas (mapas mentais, mapas conceituais, fluxogramas ou diagramas) podem representar esse quadro interativo proposto e contribuir para o desenvolvimento de roteiros que façam uso das técnicas de gamificação especificamente para programas televisivos? (4) Como o roteiro, com ações bem direcionadas e encadeadas, pode revelar a mecânica subjacente de um jogo, conduzindo o usuário a alcançar metas claras e bem definidas?

Um sistema de gamificação, embora não seja um jogo completo, o qual utiliza extensivamente a narrativa, também apresenta um forte componente narrativo que pode ser inserido à estrutura dramática, nesse caso, para a roteirização do aplicativo do programa, com a presença dos elementos de gamificação embutidos nesse contexto. Nesse sentido, pode-se desenvolver uma ou mais narrativas paralelas à narrativa principal do roteiro, cuja principal finalidade seja envolver o usuário a interagir com conteúdo televisivo educativo. A utilização do termo "conteúdo" é mais apropriada nesse contexto, pois os níveis de complexidade ou hierarquia de um ambiente digital interativo hipermídiático, em direção à compreensão do usuário (GOSCIOLA, 2003, p.84).

Neste trabalho, há o enfoque para o desenvolvimento do roteiro interativo que não é voltado somente para ao ambiente da Internet, mas também à televisão digital 
interativa, devido à implantação do SBTVD-t - Sistema Brasileiro de TV Digital Terrestre. Assim, deve haver um maior conhecimento dos roteiristas sobre a produção nesta mídia, uma vez que outros tipos de roteiros, como o roteiro literário e o roteiro técnico, não trazem as especificações necessárias para o acréscimo da interatividade. No roteiro literário, a narrativa é vista como um todo, dividida em cenas ou sequências, enquanto o roteiro técnico é uma descrição objetiva relacionada às diretrizes que facilitam o trabalho da equipe de produção de vídeo. Tendo em vista esse objetivo, é preciso trazer o conceito de gamificação, que é definida como "[...] o uso dos elementos do design de jogos em contextos não jogos" (DETERTING et al., 2011, p.2), e, então, situá-la no contexto de aprendizagem em televisão digital interativa. Kapp (2012), ao retomar esse conceito para o contexto da educação, amplia essa definição e descreve-a como o uso de mecânica de jogos, estética lúdica e pensamento de jogo para engajar pessoas, motivar ações, promover aprendizado e resolver problemas. Desta forma, na educação, gamificação representa aprender através dos games. No contexto da televisão, o conceito definido como edutretenimento (AMÉRICO; YONEZAWA, 2009, 2010) refere-se a “[...] programas que utilizam diversas mídias para incorporar mensagens educativas em formatos de entretenimento, ou seja, educam com métodos de entretenimento." (WALLDÉN; SORONEN, 2004). Por conseguinte, para que um aplicativo educativo apresente os elementos citados por Kapp (2012), é preciso que haja uma preocupação com o conteúdo e a forma, ou seja, sobre o que e como será apresentado. Field (1995, p.2), afirma que o “[...] roteiro é uma história contada em imagens, diálogos e descrições, localizada no contexto da estrutura dramática”. O roteiro não apresenta apenas a história a ser contada, mas deve apresentar também os elementos operacionais, técnicos e de interatividade. É nesse contexto, que os elementos dos jogos devem ser inseridos no roteiro, sinalizando em qual momento deverá ocorrer a interatividade, a partir de uma narrativa previamente desenvolvida. Com os recursos das novas mídias, Gosciola (2003, p.17), afirma que as narrativas deixaram de ser simples, “[...] podendo ser apresentadas por diversos pontos de vista, com histórias paralelas, com possibilidades de interferências na narrativa, com opções de continuidade ou descontinuidade da narrativa e muito mais". Sendo assim, os modelos de roteiros disponíveis e oriundos de um mundo analógico e linear já não dão mais conta de atender à produção dos produtos midiáticos, que cedem espaço para a utilização de diversos recursos e também para a hibridização de linguagens que incluem a interatividade, principalmente a partir da inserção dos elementos dos jogos ao roteiro. 


\section{Concepção de aplicativos educativos interativos para televisão}

Existe, na televisão brasileira, um desprestígio em relação aos programas educativos que reproduzem, muitas vezes, um caráter formal de aprendizagem do ambiente escolar. São raras as exceções de programas educativos que conseguem, de fato, prender a atenção das crianças e adolescentes e, até mesmo do público adulto. Em virtude disso, a geração de nativos digitais (PRENSKY, 2001) já não assiste mais à televisão na mesma proporção em que acessam e consomem os seus conteúdos preferidos na Web, como filmes, músicas, games e plataformas diversas de compartilhamento de vídeos e fotos, inclusive redes sociais e de aprendizagem.

Com a implantação da TV Digital no Brasil, surge a necessidade de se fomentar a concepção e produção de conteúdo audiovisual interativo para diferentes tipos de programação, gêneros e formatos televisivos, possibilitando um aumento significativo na oferta de conteúdos, que possam entreter e, ao mesmo tempo, instruir e incentivar a participação de um novo público ou audiência, a fim de proporcionar experiências interativas e de entretenimento. A exemplo da estratégia de desenvolvimento de aplicativos móveis, que aumentam consideravelmente a cada ano, os fabricantes de televisão procuram investir também no desenvolvimento de conteúdo para as TVs. Pelo fato de o desenvolvimento ser ainda incipiente, existe a necessidade de se aumentar a oferta de diferentes aplicativos para o ecossistema audiovisual. Em qualquer sistema de TV Digital Interativa, seja no ambiente Ginga - padrão criado para a televisão brasileira - ou em TVs Conectadas e Inteligentes, como SmartTVs, a intenção primordial é que se avance na distribuição de conteúdos, paralelamente ao universo digital dos tablets e smartphones, oportunizando novas experiências de interatividade aos seus usuários. Em termos de tendência, nota-se que os aplicativos das segundas mídias (ou segunda tela) são desenvolvidos mais especificamente para estes tipos de dispositivos, enquanto os aplicativos da primeira mídia (ou primeira tela) começam a ser desenvolvidos com pertinência às obras televisivas, com conteúdos relacionados ou complementares aos programas. No entanto, ainda que haja distinção entre os diferentes usos das mídias, a tela em si pouco importa, visto que vários aplicativos usuais e populares são convergentes em diversos dispositivos ou gadgets/devices.

As obras audiovisuais educacionais podem ser destinadas às salas de aula ou à Internet (ensino à distância), com exclusivo objetivo educacional. No entanto, para além destes objetivos formais, é preciso que as empresas de TV e vídeo, da área de produção 
de conteúdo e distribuição, desenvolvam modelos diferenciados de programação educativa, a começar por novos formatos e linguagens, como os programas baseados no conceito de Edutretetenimento. A televisão é a mídia que, por excelência, pode trazer entretenimento e educação de qualidade aos seus usuários. Dessa forma, ao se estabelecer diferentes interfaces comunicativas, a partir da linguagem digital dos games, enfatiza-se a hibridização de linguagens no ambiente televisivo que ampliam as possibilidades de comunicação e interatividade, principalmente se houver uma narrativa envolvente, capaz de permitir a troca e a transformação das informações.

A concepção de aplicativos requer uma nova forma de produção de conteúdos interativos e não-lineares, que apresentem interfaces de interação com os conteúdos principais ou extras dos programas. Além disso, deve-se planejar a narrativa do processo comunicativo para cada tipo de público-alvo, inclusive observando seus principais interesses, perfis e motivações. Independentemente de plataforma, os aplicativos devem permitir que o usuário tenha acesso às demais informações disponibilizadas para ele. No entanto, em se tratando de programas educativos para a televisão brasileira, não é apenas o conteúdo em si que deve ser questionado, mas o tipo de linguagem e formato de apresentação, capaz de engajar o usuário no desenvolvimento de seu conhecimento e criticidade. Os aplicativos educativos para a televisão devem ofertar conteúdos que atraiam a atenção do usuário e, sobretudo, contemplem a cultura do entretenimento e a qualidade da informação.

\section{Relação entre gamificação e televisão}

A gamificação é a visão do design de games sobre as coisas, tornando as atividades corriqueiras mais dinâmicas, divertidas e envolventes, através da implementação de elementos de jogos, tais como rankings, badges (medalhas), pontos, mudança de níveis etc. De acordo com Bunchball (BATEMAN GROUP, 2014) ${ }^{4}$, a gamificação permite a integração da dinâmica do jogo em um site, serviço, comunidade, conteúdo ou campanha, com a finalidade de motivar e engajar os seus usuários. Dessa forma, o usuário/telespectador ao interagir com os conteúdos do programa educativo, através de um aplicativo que apresente um sistema de gamificação, poderá se divertir e

\footnotetext{
${ }^{4}$ Bunchball é uma empresa de tecnologia que oferece serviços de gamificação para plataformas através de softwares baseado na nuvem, a fim de fidelizar clientes e empresas, através do engajamento online com a mecânica de games.
} 
aprender ao mesmo tempo, enquanto assiste ao programa, vencendo desafios, seguindo regras, ganhando premiações e passando para outros níveis, em que novos e importantes conceitos são apresentados.

Com base na metodologia proposta por Hegenberg (1974), que trata sobre os critérios válidos para a construção de um verbete, a pesquisa propôs, inicialmente, a relação entre gamificação e TV digital interativa, em forma de conceito, a fim de se poderem compreender as características, limites e possibilidades para a construção de um aplicativo educativo televisivo. A seguir a proposição do verbete (AMÉRICO; COSTA NAVARI, 2013):

Gamificação-TVDI: é o uso da mecânica de jogos e técnicas do design de games em contexto de não jogos a fim de envolver e engajar os usuários para a mudança de comportamento, visando à participação e à interação, frente à oferta de conteúdos interativos, de programas de entretenimento informativo ou educativo que tem por plataforma a TV Digital Interativa. Tem por características principais:

- Opções de escolha e participação voluntária;

- Engajamento do telespectador;

- Sistema de fidelização da audiência;

-Solução interativa para aumentar as possibilidades de aprendizagem no ambiente da televisão;

- Agregação de pontos, níveis, emblemas ou medalhas, rankings e recompensas, na interação do telespectador com os aplicativos e conteúdos televisivos;

- Permitir a interação e a competitividade de jogo, a partir das plataformas sociais;

- Aplicação conjunta em múltiplas plataformas, em mídia primária (TV) e mídias secundárias (dispositivos móveis, como os smartphones e tablets);

- Rápido ciclo de feedback relacionado ao desempenho, a fim de melhorar a experiência do usuário.

- Incorporação da narrativa como contexto dos objetivos, de forma convincente para envolver os telespectadores à participação e alcance das metas;

- Incentivo à progressão;

- Objetivos claros e regras bem definidas;

- Atividades desafiadoras e alcançáveis;

- Atrair o público consumidor de mídias digitais;

- Linguagem e estética visual dos elementos dos games;

-Entretenimento televisivo mais lúdico, divertido e participativo. (AMÉRICO; COSTA-NAVARI, 2013, p.87, grifo nosso). 
Após a proposição do verbete, em que se tratou da relação entre gamificação e TVDI, vislumbrou-se, a necessidade de se propor um novo modelo de concepção de roteiros interativos que ofereçam, além da estrutura dramática, o pensamento, a mecânica e os elementos de jogos, capazes de proporcionar engajamento e interatividade com o conteúdo ofertado. Dessa forma, é preciso reinventar o design atual dos programas educativos, tendo o roteiro como ponto de partida para esta construção de hibridização com outras linguagens no ambiente hipermidiático televisivo. $\mathrm{O}$ exercício da criatividade em roteirização, com base em conceitos de interatividade e imersão, permite, pois, traçar alguns caminhos, capazes de trazer diversas opções de condução narrativa ao usuário.

\section{Processo de criação de roteiro interativo a partir de mapas conceituais}

$\mathrm{Na}$ área acadêmica do audiovisual, não há ainda, no Brasil, um número significativo de pesquisas sobre o desenvolvimento de roteiros interativos, porém, partindo da necessidade de se poder representar o roteiro. Este trabalho desenvolve um modelo de roteiro para aplicativos educativos interativos, através de mapas conceituais, com o objetivo de indicar proposições a respeito das relações existentes entre os elementos que compõem a produção de conteúdo audiovisual, considerando não apenas o áudio e o vídeo, como também os elementos interativos, provenientes da gamificação. Para Belda (2009), os modelos empregados atualmente no processo de produção de conteúdo audiovisual para educação são limitados para os objetivos a que estão propostos, principalmente na produção de conteúdos que permitam a interação do usuário.

O processo de desenvolvimento de roteiro tem sido o mesmo há muitos anos, seguindo o modelo clássico que apresenta o fluxo de informações lineares e sequenciais, organizadas em duas colunas, uma para áudio e outra para vídeo. No entanto, essa estrutura já não é mais capaz de suportar o desenvolvimento das novas mídias digitais, inclusive para diferentes tipos de suportes.

Em 2005, durante as pesquisas para o Sistema Brasileiro de TV Digital (SBTVD), Crocomo (2009) desenvolveu a partir de um software de autoria, um modelo de roteiro interativo com a terceira coluna da interatividade, em que podiam ser descritas as informações adicionais na tela (texto e/ou gráfico), enquetes e vídeos adicionais ao fluxo principal. Embora este tipo de roteiro tenha possibilitado o 
acréscimo da coluna da interatividade, com a inserção de informações adicionais, num determinado tempo e espaço, elas apenas acompanham o fluxo principal, não podendo ser levado em conta o ponto de vista do usuário. Para Gosciola (2003), o roteirista, ao desenvolver o roteiro, deve considerar as possibilidades de o usuário percorrer caminhos diferentes, visto que as novas mídias oferecem diversos recursos e devem nascer da soma entre o desenvolvimento tecnológico e estético. No entanto, é preciso considerar as diferentes possibilidades e limitações durante a construção de um roteiro interativo que atenda, pelo menos, às exigências de produção deste novo tipo de mídia. Para uma melhor estratégia de compreensão semântica do roteiro, a utilização de mapas conceituais é essencial para a clareza proposicional dos conceitos, a fim de se poderem demonstrar, mais precisamente, como os elementos de gamificação podem estar presentes neste contexto.

O roteiro é o texto que desenvolve um argumento e indica como deve realizar-se qualquer tipo de obra audiovisual. Com a interatividade, o roteiro não apenas transmite mensagens através de som e imagem, mas também através de dados, como no caso da televisão digital. Dessa forma, deve haver uma descrição pormenorizada dos elementos relativos à interatividade, com objetividade e clareza, a fim de contribuir para o desenvolvimento de diversos produtos midiáticos. Essa reflexão culmina, pois, para o entendimento do primeiro questionamento deste trabalho: Até que ponto a construção de significados e o encadeamento de ações e elementos visuais e interativos no roteiro, em uma relação de causa e efeito, podem contribuir para o engajamento do usuário frente à oferta de conteúdos interativos?

Ao se descrever os eventos de causa e efeito, no mapa conceitual (definido logo adiante), o roteiro deixa de ser necessariamente linear, com começo, meio e fim, ou em sequência cronológica, e permite maior liberdade de interferência do usuário em conteúdos não-lineares e interativos. No entanto, para que o roteiro atinja estes objetivos, ele deve ser funcional, em sua fase conceitual, o que significa desenvolver um roteiro bem escrito, com encadeamento de ações e elementos visuais, que possam facilitar o trabalho conjunto da equipe de software e gravação para a fase de produção.

$\mathrm{O}$ roteiro interativo deve ser um documento escrito da forma mais simples possível, com a descrição do conteúdo da linguagem de conversação e dos elementos interativos associados ao contexto da trama, ou ainda, para os conteúdos complementares e adicionais. Para o desenvolvimento desse tipo de roteiro, com narrativas não-lineares, serão utilizados mapas conceituais, visto que eles permitem a 
organização e a representação do conhecimento, a partir de conceitos (fechados em círculos) e das proposições que relacionam dois ou mais conceitos (por meio de linhas que ligam palavras ou frases). Os mapas conceituais foram desenvolvidos em 1972, por Novak (1984), enquanto ele pesquisava o conhecimento das crianças sobre ciência, tendo por base os estudos de Ausubel (1983) acerca da aprendizagem significativa, que ocorre pela assimilação de novos conceitos e proposições em vista dos conceitos e estruturas já existentes. Com a intenção, pois, de encontrar uma maneira melhor para representar o entendimento conceitual das crianças, surgiu a ideia de utilizar mapas conceituais, através do desenvolvimento de uma ferramenta, conhecida como Cmap Tools (CABRAL, 2003), que veio a ser utilizada posteriormente para as demais áreas do conhecimento.

A concepção de roteiros em formato de mapas conceituais facilita a comunicação e o compartilhamento da informação no processo de roteirização, visto que envolve uma equipe multidisciplinar. Gosciola (2003, p.158) afirma que “[...] em geral, o roteiro vem sendo desenvolvido por pelo menos três profissionais: o desenvolvedor de conteúdo, o responsável pela arquitetura da informação e o designer de hipermídia”. Dessa forma, entende-se que o roteiro deva ser essencialmente visual, com clareza entre os conceitos e proposições, a fim de que a equipe de produção trabalhe de forma alinhada para o desenvolvimento de roteiros e aplicativos para a televisão digital interativa.

No entanto, será que existem limites e possibilidades ao se trabalhar os elementos dos jogos no desenvolvimento do roteiro audiovisual? Para a confecção de um roteiro não se pode estabelecer regras, pois um roteiro reproduz as subjetividades e a criatividade de cada profissional com suas ideias:

[...] roteirizar ideias envolve, além dos próprios sentimentos, uma técnica de indução, persuasão, e o conhecimento da mídia que se vai trabalhar. $\mathrm{O}$ seu roteiro tanto pode ser veiculado em circuitos fechados ou em broadcasting, nos mais variados gêneros e formas. (SABOYA, 2001, p.46).

Além da arte de escrever roteiros, o profissional precisa conhecer e desenvolver novas técnicas para hibridizar outras linguagens ao audiovisual, o que amplia as suas possibilidades. Girondi $(2012$, p.99) afirma que “[...] o roteiro na forma de mapa 
conceitual dá conta justamente de revelar a não-linearidade tanto da história quanto do processo de elaboração".

Por esta razão, conclui-se que é possível o desenvolvimento do roteiro nesse formato, podendo, pois, representar os diversos tipos de interação com o conteúdo, a partir dos elementos de gamificação. Essas interações, segundo Gosciola (2003), podem ser oferecidas por meio de links que direcionam o usuário para as demais narrativas paralelas, além de permitir imersão na história e liberdade para a condução não-linear da narrativa, de acordo com seu grau de interesse. À medida que o usuário interage com o conteúdo do programa educativo, ele pode verificar a sua progressão de forma dinâmica, através dos pontos, medalhas e rankings, entre outros elementos visuais que indicam novas metas e níveis a serem alcançados. Esses elementos são implementados desde a concepção do roteiro, e podem ser acessados via aplicativo do programa, no próprio suporte de mídia televisiva ou ainda em outros dispositivos móveis.

\section{Modelagem de conteúdo}

A modelagem é uma técnica que auxilia na representação dos processos de desenvolvimento de qualquer produto midiático. Ela requer o conhecimento das linguagens de notação empregadas para a construção de modelos e que sejam apropriadas para o contexto de sua aplicação. Neste trabalho, optou-se pela escolha de um modelo de fácil entendimento, como o Mapa Conceitual, a partir da ferramenta Cmap Tools (CABRAL, 2003), para a representação do roteiro, um documento imprescindível na fase de pré-produção do produto audiovisual e, também, o Technology Roadmapping (TRM) (PHAAL; PROBERT, 2009), para a definição do processo da pesquisa e das metas de aplicações futuras. Dessa forma, essa metodologia de trabalho responde à terceira pergunta da pesquisa: de que forma as notações textuais e gráficas (mapas mentais, mapas conceituais, fluxogramas ou diagramas) podem representar esse quadro interativo proposto e contribuir para o desenvolvimento de roteiros que façam uso das técnicas de gamificação especificamente para programas televisivos? Na figura 1, a seguir, há a representação de um roteiro geral, em visão macro, para a compreensão de como seria a implementação dos elementos de gamificação (dados), simultaneamente ao contexto do fluxo interativo da cena (áudio e vídeo): 
Figura 1 - Estrutura básica de roteiro com sequências interativas - inserção de dados gráficos (elementos de gamificação)

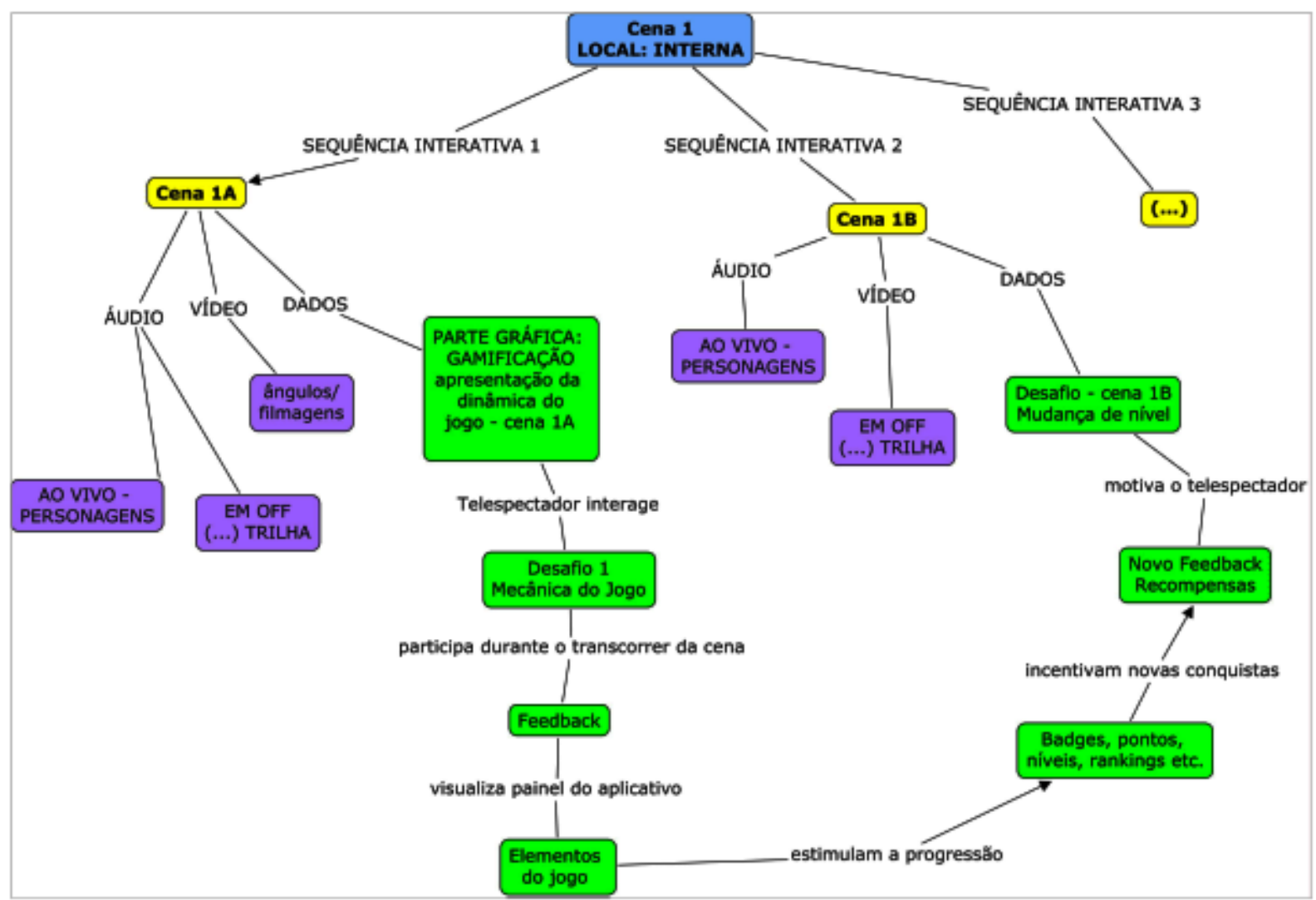

Fonte: Elaborada pelos autores.

O mapa conceitual, acima, reproduz de forma simplificada, a estrutura de um roteiro interativo, devendo o mesmo ser mais bem elaborado, de acordo com as especificidades e objetivos do conteúdo educativo a ser desenvolvido. As sequências interativas da cena 1A, descritas no mapa, explicitam que é possível atrelar a narrativa, o pensamento e os elementos de jogos à estrutura dramática de um programa educativo, dando continuidade das regras e mecânica de jogos durante o transcorrer das cenas (cena 1B), possibilitando ao usuário a progressão e o alcance de pontos e recompensas.

Camargo (2011) explicita a necessidade de determinar alguns componentes imprescindíveis, antes de elaborar um roteiro interativo: (a) definir o programa; (b) definir o conteúdo (lexia, níveis de complexidade); (c) definir o argumento (local, fatos, época; (e) definir o tipo de interação (apresentação, escolha, jogo); (f) definir o tipo de mídias para a interação; $(\mathrm{g})$ definir a tela principal; $(\mathrm{h})$ definir o conceito de menu, a relação de objetos e palavras para o público-alvo; (i) definir o tempo de permanência da 
informação; (j) definir o nível de interação e a ordem de apresentação; (l) definir a orientação ao espectador sobre o uso da interação; (m) definir a interface (design, metáfora). Dessa forma, subentende-se que, ao criar um roteiro interativo, é preciso concebê-lo, elaborá-lo e construí-lo, de acordo, com as necessidades e especificações dos objetivos do programa, alinhados ao público-alvo.

Então, em resposta à ultima questão do trabalho, como o roteiro com ações bem direcionadas e encadeadas, pode revelar a mecânica subjacente de um jogo, conduzindo o usuário a alcançar metas claras e bem definidas? Nesse caso, além de pesquisar o conteúdo educativo para a concepção do roteiro, é preciso, antes de tudo, pensar como um designer de jogos que usa a sua criatividade para criar experiências que tragam emoção, diversão e motivação aos usuários/jogadores. Portanto, o maior desafio da gamificação é criar um design que envolva mecânica, estética e narrativa com elementos de jogos. Lembrando que gamificação não é um jogo, mas uma experiência que envolve o usuário, a fim de obter melhores resultados em diferentes áreas não-jogo, além de aumentar o engajamento e o tempo gasto em qualquer atividade proposta.

A partir da proposição feita por Manrique (2013), antes de criar um design de gamificação, a começar pelo roteiro propriamente dito, é preciso atentar para os quatro passos essenciais para desenvolver uma experiência de gamificação: (1) Por quê? (objetivo); (2) O quê? (ações); (3) Quem? (usuários/jogadores); (4) Como? (sistema).

Figura 2 - Os quatro passos para desenvolver uma experiência de gamificação

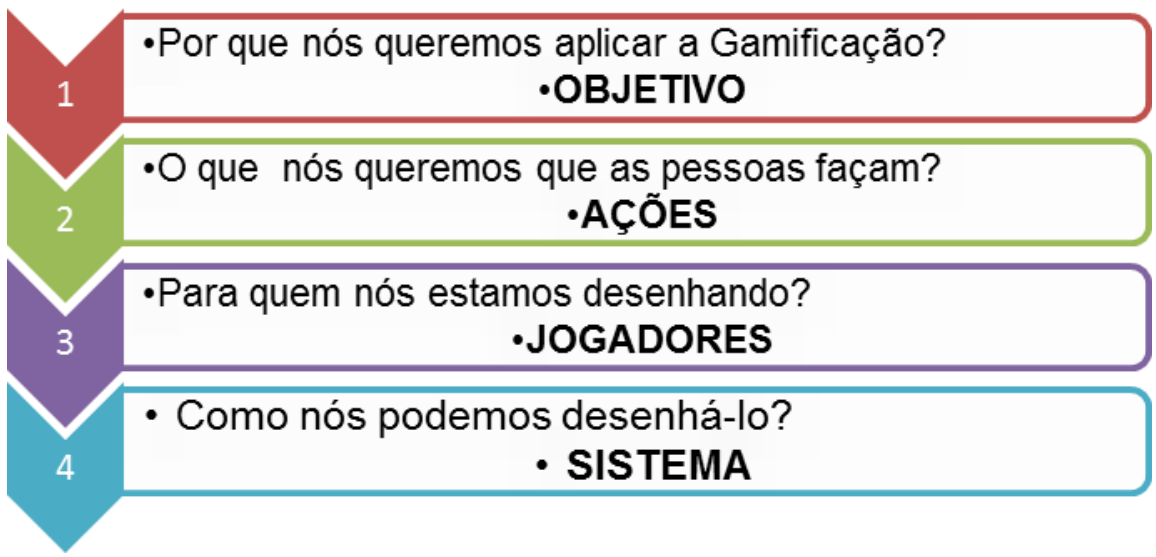

Fonte: Manrique (2013, tradução e adaptação nossa).

A primeira pergunta, inserida no contexto de produção do roteiro seria: por que aplicar a gamificação em programas ou aplicativos educativos para a televisão? Porque o objetivo é proporcionar aprendizado e entretenimento aos usuários, através de 
experiências que os levem a realizar atividades que antes eram consideradas monótonas. $\mathrm{O}$ que seria mais interessante para as crianças e jovens? Um programa de televisão similar ao ambiente educativo ou um programa rico de recursos de interatividade e de estímulos? Além disso, a gamificação permite o crescimento viral (no sentido usado na internet) capaz de atrair mais usuários/jogadores para o sistema. O próximo passo é pensar quais ações devem ser tomadas a fim de alcançar esse objetivo, considerando-se a mecânica, a estética e a narrativa apropriadas, em vista dos comportamentos desejados e esperados do usuário/jogador. Dessa forma, o terceiro passo consiste em conhecer o perfil do público, o que de fato os motiva, para, então, oferecer-lhes algo em troca que lhes dê satisfação enquanto ele busca por aprendizado, informação e entretenimento. $O$ quarto e último passo trata especificamente sobre a modelagem de um sistema de gamificação, ou seja, desenhar o projeto como se fosse um processo interativo (protótipo) que envolve a aplicação da mecânica, estética e narrativa de jogo. Assim, é possível embutir os elementos de jogos tanto ao roteiro da estrutura dramática das cenas, como também desenvolver um sistema geral de gamificação do programa no aplicativo educativo - como plataforma de acesso a todos os conteúdos disponibilizados pela emissora - de modo que haja participação do público e fidelização da audiência

Figura 3 - Modelo de um sistema de gamificação para aplicativo com acesso aos conteúdos complementares do programa educativo

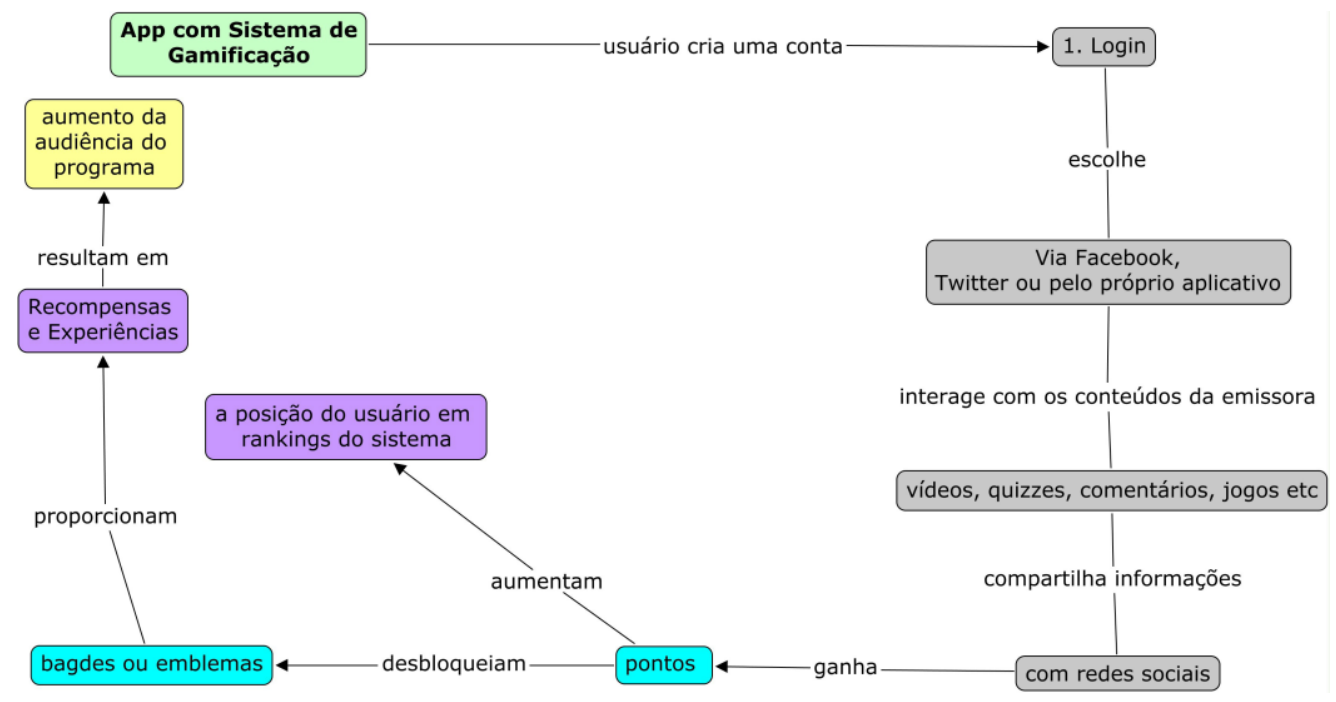

Fonte: Elaborada pelos autores.

Enfim, tanto a modelagem do roteiro do programa quanto a modelagem para o desenvolvimento do aplicativo são essenciais para a produção de novos produtos 
midiáticos e audiovisuais, principalmente em virtude das novas práticas narrativas utilizadas para o entretenimento da audiência.

\section{Modelagem de processo}

Este trabalho foi concebido como um processo, a fim de revelar as suas etapas de desenvolvimento. Para tanto, foi utilizada a abordagem do TRM - Technology Roadmapping (PHAAL; PROBERT, 2009), que auxilia no gerenciamento do tempo em relação às metas para a realização do produto, nesse caso, do roteiro para o programa e do seu aplicativo de interação. O roadmap é, na verdade, o resultado desse processo, em que se podem verificar as tecnologias necessárias para satisfazer essas necessidades, bem como o mecanismo que ajuda a prever e a planejar evolução dos produtos em desenvolvimento. Para o desenvolvimento de um roadmap, seja no contexto de uma empresa ou no desenvolvimento de pesquisas acadêmicas, deve-se levar em conta que a gestão dos produtos (figura 4) depende dos objetivos e metas previamente estabelecidas, das necessidades dos usuários, bem como da tecnologia disponível para a produção.

Figura 4 - Requisitos para o desenvolvimento de um roadmap

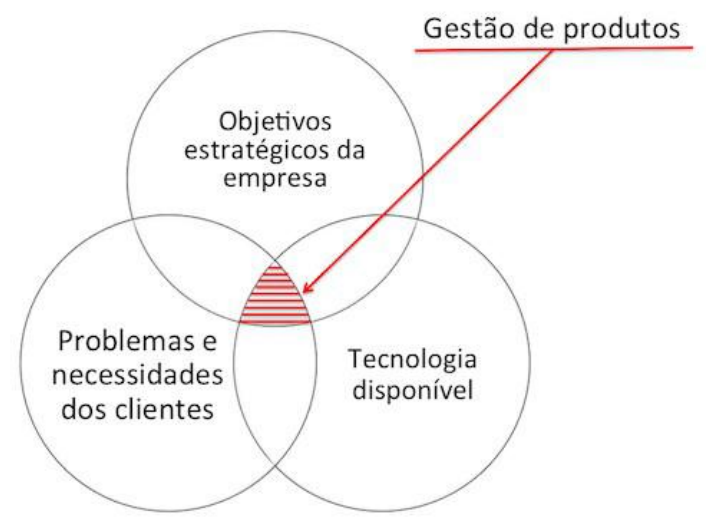

Fonte: Guia da startup e de gestão de produtos de software (2014).

No entanto, no contexto acadêmico, os roadmaps vem sendo gerados, particularmente, em universidades empreendedoras ou spin-offs acadêmicos (SHANE, 2004), com a finalidade de visualizar a evolução da estratégia de negócio, desde a sua concepção (planejamento inicial) até o desenvolvimento do produto (GOMES; 
SALERNO, 2010). Dessa forma, o método TRM serve como elo de integração entre esses dois processos para auxiliar pesquisadores/empreendedores no desenvolvimento de empreendimentos atuais ou futuros. A partir de uma estratégia preditiva, o roadmap dessa pesquisa (figura 5), configura-se da seguinte maneira:

Figura 5 - Roadmap do processo da pesquisa acadêmica com projeções futuras para protótipo comercial

\begin{tabular}{|c|c|c|c|c|}
\hline$\underline{\text { TEMPO }}$ & $\begin{array}{c}2013 \\
Q 1-Q 2\end{array}$ & $\begin{array}{c}2013 \\
Q 3-Q 4\end{array}$ & $\begin{array}{c}2014 \\
Q 1-Q 2\end{array}$ & $\begin{array}{c}2014 \\
Q 3-Q 4\end{array}$ \\
\hline $\begin{array}{l}\text { MERCADO } \\
\text { Problemas e } \\
\text { necessidades } \\
\text { dos usuários }\end{array}$ & \multicolumn{4}{|c|}{$\begin{array}{l}\text { - Evolução das mídias analógicas para as mídias digitais; Gamificação } \\
\text { como estratégia para o engajamento dos usuários; } \\
\text { - Ausência de programas educativos interativos; } \\
\text { - Necessidade de novo formato de roteirização para produtos } \\
\text { midiáticos emergentes; } \\
\text { - Desenvolvimento de ap licativos de interação com o ecoss istema } \\
\text { televisivo (conteúdos complementares relacionados aos programas). }\end{array}$} \\
\hline PRODUTO & $1^{3}$ Etapa & cont. $1^{3}$ Etapa & $2^{\circ}$ Etapa & $3^{2}$ Etapa \\
\hline$\frac{\text { ROTEIRO }}{\text { INTFRATIVO }}$ & (Conceitual) & (Conceitual) & $\begin{array}{l}\text { (Protótipo Visuale } \\
\text { Conceitual) }\end{array}$ & (Protótipo final) \\
\hline $\begin{array}{l}\text { Objetivos } \\
\text { eetapas da } \\
\text { pesquisa }\end{array}$ & $\begin{array}{l}\text { Bibliográfica e } \\
\text { documental, } \\
\text { revisão de } \\
\text { literatura; } \\
\text { estudo de } \\
\text { caso. }\end{array}$ & $\begin{array}{l}\text { Bibliográfica e } \\
\text { documental, } \\
\text { revisão de } \\
\text { literatura; } \\
\text { estudo de } \\
\text { caso. }\end{array}$ & $\begin{array}{l}\text { Descritiva e } \\
\text { qualitativa, } \\
\text { desenvolvimento de } \\
\text { modelos de roteiro } \\
\text { interativo } \\
\text { paraprograma } \\
\text { educativo e seu } \\
\text { aplicativo de } \\
\text { interação. }\end{array}$ & $\begin{array}{l}\text { Experimental- } \\
\text { Aplicação de técnicas } \\
\text { para a confecção do } \\
\text { roteiro interativo do } \\
\text { programa e das telas } \\
\text { do aplicativo, com } \\
\text { implementação dos } \\
\text { elementos visuais de } \\
\text { gamificação. }\end{array}$ \\
\hline $\begin{array}{c}\text { Fontes } \\
\mathrm{e} \\
\text { Recursos }\end{array}$ & $\begin{array}{l}\text { Livros, Intemet, } \\
\text { documentos, } \\
\text { plataformas } \\
\text { com sistemas } \\
\text { de } \\
\text { Gamificação. }\end{array}$ & $\begin{array}{l}\text { Livros, Intemet, } \\
\text { documentos, } \\
\text { plataformas } \\
\text { com sistemas } \\
\text { de } \\
\text { Gamificação. }\end{array}$ & $\begin{array}{l}\text { Mapas Conceituais, } \\
\text { mapas mentais, } \\
\text { diagramas. }\end{array}$ & $\begin{array}{l}\text { Elementos de } \\
\text { Gamificação (PBL); } \\
\text { Open Badges; } \\
\text { ferramentas de } \\
\text { edição de roteiroe } \\
\text { wireframes/ } \\
\text { protótipos de baixa } \\
\text { fidelidade; Modelo } \\
\text { Canvas de } \\
\text { Gamificação. }\end{array}$ \\
\hline
\end{tabular}

Fonte: Elaborada pelos autores.

\section{Considerações Finais}

Com a finalidade de contribuir para os processos de inovação e pesquisa, a partir das tecnologias digitais dos jogos, tomou-se, nesse trabalho, o conceito-base de gamificação como ponto de partida para o desenvolvimento do verbete "GamificaçãoTVDI", contribuindo, assim, para o conhecimento dos elementos dos games, aplicáveis na concepção de roteiros dos programas educativos e seus aplicativos de interação. 
Tendo em vista a implementação desses elementos, no desenvolvimento do roteiro interativo, a pesquisa pôde constatar que os roteiros tradicionais para a televisão analógica não são suficientes para representá-los, tendo, pois, que desenvolver roteiros interativos no formato de mapas conceituais. A partir do exercício de modelagem, foi possível concluir que as representações gráficas desses modelos, além de facilitarem o trabalho da equipe multidisciplinar durante o processo de produção, ainda permitem que, ao final, o usuário possa ter maior liberdade de escolha em conteúdos interativos e não lineares, ampliando, assim, as possibilidades de informação, entretenimento e aprendizagem.

A modelagem de conteúdo e de processo apresentada nessa pesquisa contribuiu não apenas para a aplicação dos elementos de games no roteiro interativo, como também permitiu acompanhar o andamento da pesquisa, através da ferramenta TRM Technology Roadmapping (PHAAL; PROBERT, 2009), o que facilitou a compreensão sobre a relação entre as necessidades do mercado, o projeto do produto e a tecnologia disponível para a sua realização, além de permitir a projeção do cenário para o desenvolvimento de futuros protótipos comerciais.

\section{GAMIFICATION: MODELING OF CONTENTS FOR PROGRAMS AND EDUCATIVE APPLICATIONS IN THE ENVIRONMENT OF INTERACTIVE DIGITAL TV}

ABSTRACT: With the deployment of Digital TV in Brazil, there is a need to foment the development and production of interactive audiovisual quality content, especially for programs that present educational messages from the entertainment concept - defined as Edutertainment. The objective of this study is to propose application of the gamification as a link of communication to encourage and modify user behavior, through a narrative that encourages intrinsic motivation for learning and entertainment in this media. This paper points out that there are few models of screenplays for applications production, particularly educational, with simultaneous interactive applications for television flow or complementary programming content offered. For this reason, a special attention is given to the screenplay, by virtue of inserting in its construction, the elements that make up the mechanics and dynamics of games. As a result, is shown the entry "Gamification-iDTV", which defines these two scenarios, as well as the development of a modeling methodology of a content and process, supported by conceptual maps, wireframes and roadmaps, substantiating the conception and elaboration of screenplay's prototype with elements of gamification for educational programs and its interaction applications.

KEYWORDS: Gamification. Screenplay writing. Edutertainment. Educational application. Interactive digital television. 


\section{REFERÊNCIAS}

AMÉRICO, M.; COSTA NAVARI, S. Gamificação: abordagem e construção conceitual para aplicativos em TV Digital Interativa. Revista GEMINIS, São Carlos, v.2, n.2, p.87-105, 2013. Disponível em:

<http://www.revistageminis.ufscar.br/index.php/geminis/article/view/163/132>. Acesso em: 17 jul. 2014.

AMÉRICO, M.; YONEZAWA, W. M. TV Digital e edutretenimento: proposta de modelo de produção de programa interativo para o ensino de ciências. In: PIROLA, N. A. (Org.). Ensino de ciências e matemática IV: temas de investigação. São Paulo: Cultura Acadêmica, 2010. p.223-244. v.1.

. TV digital, t-learning e edutretenimento. In: CALDEIRA, A. M. A. (Org.). Ensino de ciências e matemática II: temas sobre formação de conceitos. São Paulo: Cultura Acadêmica, 2009. p.221-238. v.2.

AUSUBEL, D. P.; NOVAK, J. D.; HANESIAN, H. Psicología educativa: un punto de vista cognoscitivo. México: Editorial Trillas, 1983.

BATEMAN GROUP. Bunchball the leader in gamification [online]. 2014. Disponível em: <http://www.bunchball.com>. Acesso em: 12 jul. 2014.

BELDA, F. R. Um modelo estrutural de conteúdos para televisão digital interativa. 2009. 296 f. Tese (Doutorado em Gestão do Conhecimento e Tecnologia de Informação) - Escola de Engenharia de São Carlos, Universidade de São Paulo, São Carlos, 2009.

CABRAL, A. R. Y. Como criar mapas conceituais utilizando o CMapTools - versão 3.x. Guaíba: ULBRA - Universidade Luterana do Brasil, 2003. Disponível em: <http://www2.ufpel.edu.br/lpd/ferramentas/cmaptools.pdf>. Acesso em: 15 fev. 2014.

CAMARGO, L. Roteiro para a TV digital interativa a partir dos pressupostos da hipermídia [online]. 2011. Disponível em: <http://www.abed.org.br/congresso2011/cd/127.pdf >. Acesso em: 05 mar. 2014.

CROCOMO, F. et al. Produção de conteúdo para TV digital e uso de ferramenta de autoria para inserção de interatividade. 2009. In: XXXII Congresso Brasileiro de Ciências da Comunicação, 2009, Curitiba.

DETERDING, S. et al. Gamification: toward a definition. Vancouver: CHI, 2011. Disponível em: <http://gamification-research.org/wp-content/uploads/2011/04/02Deterding-Khaled-Nacke-Dixon.pdf>. Acesso em: 05 jul. 2013.

FIELD, S. Manual do roteiro: os fundamentos do texto cinematográfico. Rio de Janeiro: Objetiva, 1995.

GIRONDI, A. A concepção de roteiros para artefatos audiovisuais digitais interativos na forma de mapa conceitual para aprimorar a disseminação do conhecimento. 2012. 162 f. Dissertação (Mestrado em Engenharia e Gestão do Conhecimento) - Universidade Federal de Santa Catarina, Florianópolis, 2012. 
GOMES, L. A. V.; SALERNO, M. S. Modelo que integra processo de desenvolvimento de produto e planejamento inicial de spin-offs acadêmicos. Gestão \& Produção, São Carlos, v.17, p.245-255, 2010.

GOSCIOLA, V. Roteiro para as novas mídias: do game a TV interativa. São Paulo: SENAC, 2003.

GUIA DA STARTUP E DE GESTÃO DE PRODUTOS DE SOFTWARE. Engenharia de protudos e gestão de produtos [online]. 2014. Disponível em:

<http://www.guiadastartup.com.br/wp-content/uploads/2012/11/gp.png>. Acesso em: 20 mar. 2014.

HEGENBERG, L. Definições: termos teóricos e significado. São Paulo: Cultrix, 1974.

KAPP, K. The gamification of learning and instruction: game-based methods and strategies for training and education. San Francisco: John Wiley \& Sons, 2012.

MANRIQUE, V. Gamification design steps [online]. 2013. Disponível em: <http://goo.gl/5PScWE>. Acesso em: 10 mar. 2014.

NOVAK, J.; CAÑAS, A. J. The theory underlying concept maps and how to construct them. Technical Report IHMC CmapTools. Florida: Florida Institute for Human and Machine Cognition, 2006. Disponível em:

<http://cmap.ihmc.us/publications/researchpapers/theorycmaps/theoryunderlyingconcep tmaps.htm>. Acesso em: 10 mar. 2014.

NOVAK, J. D.; GOWIN, D. B. Learning how to learn. New York: Cambridge University Press, 1984.

PHAAL, R.; PROBERT, D. Technology roadmapping: facilitating collaborative research strategy. Cambridge: Institute of Manufacturing, University of Cambridge, 2009. Disponível em:

<http://www2.ifm.eng.cam.ac.uk/ctm/trm/documents/roadmapping_overview.pdf >. Acesso em: 10 jul. 2014.

PRENSKY, M. Digital natives, digital immigrants. On the Horizon, Lincoln, v.9, n.5, oct. 2001.

SABOYA, J. Manual do autor-roteirista: técnicas de roteirização para a TV. 2.ed. Rio de Janeiro: Record, 2001.

SHANE, S. Academic entrepreneurship: university spinoffs and wealth creation. Northampton: Edward Elgar, 2004. Disponível em: <http://goo.gl/bYKcbD>. Acesso em: 20 mar. 2014.

WALLDÉN, S.; SORONEN, A. Edutainment: from television and computers to digital television. Tampere: University of Tampere hypermedia laboratory, 2004. Disponível em: <http://www.uta.fi/hyper/julkaisut/b/fitv03b.pdf >. Acesso em 05 de jul. 2013. 